\title{
The safety future of fruit preservation with biomaterials
}

\begin{abstract}
Food quality preservation is as important as with food production. It is highly necessary for ensuring food security and sustainability on the earth. However, at the same time, food preservation methods, i.e. agrochemicals, may cause some food safety issues under misuse and/or excessive use conditions. Therefore, safety methods should be studied by the scientific world and to be commercialized by the industries for ensuring food safety and security. Herein, biomaterials are the most promising and safety alternatives to the agrochemicals. In this perspective paper, we aimed to highlight the importance of the subject and to summary the critical points (importance, advantages, disadvantages, mode of action and successful application) of the biomaterials for lighting the way for new researchers to commercialize such techniques. We believe that the biomaterials constitute an important part within the safety future of fruit preservation.
\end{abstract}

Keywords: fruit preservation, biomaterials, food quality, food security, physico-chemical changes

\author{
Volume 4 Issue 6 - 2020 \\ İbrahim Kahramanoğlu,' Chuying Chen, ${ }^{2}$ \\ Kannan RR Rengasamy, ${ }^{3}$ Chunpeng Wan ${ }^{2}$ \\ 'European University of Lefke, Gemikonagi, Northern Cyprus, \\ Turkey \\ ${ }_{2}^{2}$ Jiangxi Key Laboratory for Postharvest Technology and \\ Nondestructive Testing of Fruits \& Vegetables/ Collaborative \\ Innovation Center of Postharvest Key Technology and Quality \\ Safety of Fruits \& Vegetables in Jiangxi Province, College of \\ Agronomy, Jiangxi Agricultural University, China \\ ${ }^{3}$ Indigenous Knowledge Systems Centre, Faculty of Natural and \\ Agricultural Sciences, North-West University, South Africa
}

Correspondence: Chunpeng Wan, Jiangxi Key Laboratory for Postharvest Technology and Nondestructive Testing of Fruits \& Vegetables/ Collaborative Innovation Center of Postharvest Key Technology and Quality Safety of Fruits \& Vegetables in Jiangxi Province, College of Agronomy, Jiangxi Agricultural University, Nanchang 330045, China, Tel +86-79|-838|3185, Email chunengwan@jxau.edu.cn

Received: October II, 2020 | Published: December 0I, 2020
Abbreviations: MDA, malondialdehyde; POD, peroxidase; PPO, polyphenol oxidase; APX, ascorbate peroxidase; CAT, catalase; SOD, superoxide dismutase

\section{Introduction}

Foods, the plant or animal originated substances, contain necessary carbohydrates, proteins, fats, vitamins and essential minerals for human health. The increase in human population has caused an increase in the need for food throughout the world. At the same time, available resources for food production, mainly soil and water, have been depleting on the earth, ${ }^{1}$ and treating food security. Besides, more than $30 \%$ of the agricultural products are never reaching to the final consumers because of the postharvest losses, ${ }^{2}$ Starting from the history of agriculture, human beings have been experimenting and adapting postharvest techniques for food preservation. Sanitation and cold storage are among the most important ones, while the understanding of food physiology made it possible to develop novel techniques. The concept of fruit coating is an old technique that dates back to the 12th century in China but was firstly commercialized around the $1920 \mathrm{~s}^{3}$ Then, widespread the use of synthetic fungicides opened a new era in postharvest handling practices after the 1940s. However, reduction of the postharvest losses had been mainly dependent on cold storage together with physical and chemical methods for many years. Furthermore, scientific confirmation of the negative impacts of misuse and/or excessive use of agrochemicals ${ }^{4}$ reduced their acceptability by the consumers. ${ }^{5}$ These, in general, lead the scientific and industrial world to turn their face to safer alternatives.

\section{Main findings and discussions}

One of the most promising alternatives to the agrochemicals is the edible coating and edible films derived from the biomaterials including plant extracts, plant-derived products, natural polymers (proteins, polysaccharides and lipids), plant-derived secondary metabolites (i.e. essential oils), chitosan, etc., ${ }^{3,6-8}$ The main difference between films and coatings is that the films are solid laminates and applied to foods where coatings are in liquid forms and applied in different methods, including dipping, spraying, brushing and coating. ${ }^{9,10}$ Biomaterials are known as environmental and human friendly because of their high biodegradability. ${ }^{11}$ Numerous studies have been performed about the potential use of biomaterials in postharvest handling practices. In one of the recent studies, Kubheka et al. ${ }^{12}$ recommended that the combination of moringa leaf extract with Arabic gum and carboxymethyl cellulose have high potential to be commercialized as an organic bio-fungicide and used in avocado storage. Fresh-cut products are now highly appreciated by the consumers due to the change in their lifestyles (modern life) but are more open to quality loss. Biomaterials are also very useful in preserving the shelf-life of fresh-cut products. ${ }^{13}$

The success of the edible coatings/films derived from the biomaterials is mainly depended on the barrier ability, adhesion potential, thickness, uniformity, plasticity, flexibility, waxiness and sensory quality. ${ }^{9}, 14$ The mode of action behind the success of biomaterials is material dependent. The main ones are the ability to reduce respiration rate, retarding ethylene production, oxidationreduction, preventing enzymatic degradation, preventing polyphenols reduction and maintaining antioxidant activity. This includes inducing phenolic biosynthesis, reducing malondialdehyde (MDA) content and inhibiting/inducing/decelerating the biosynthesis of some enzymes, i.e., peroxidase (POD $\downarrow$ ), polyphenol oxidase (PPO $\downarrow$ ), ascorbate peroxidase (APX $\uparrow)$, catalase (CAT $\uparrow$ ) and superoxide dismutase (SOD $\uparrow$ ). ${ }^{9,15,16}$ Besides to the biodegradability and safety, the main advantages/outcomes of the biomaterials in postharvest practices are 
retarding ripening, prolongation of the storability, pathogen inhibition ability, improvement of the appearance, delaying Physico-chemical changes, improving firmness, flavour retention, maintaining soluble solids and titratable acidity and reducing enzymatic browning ${ }^{3,9}$ (Figure 1).

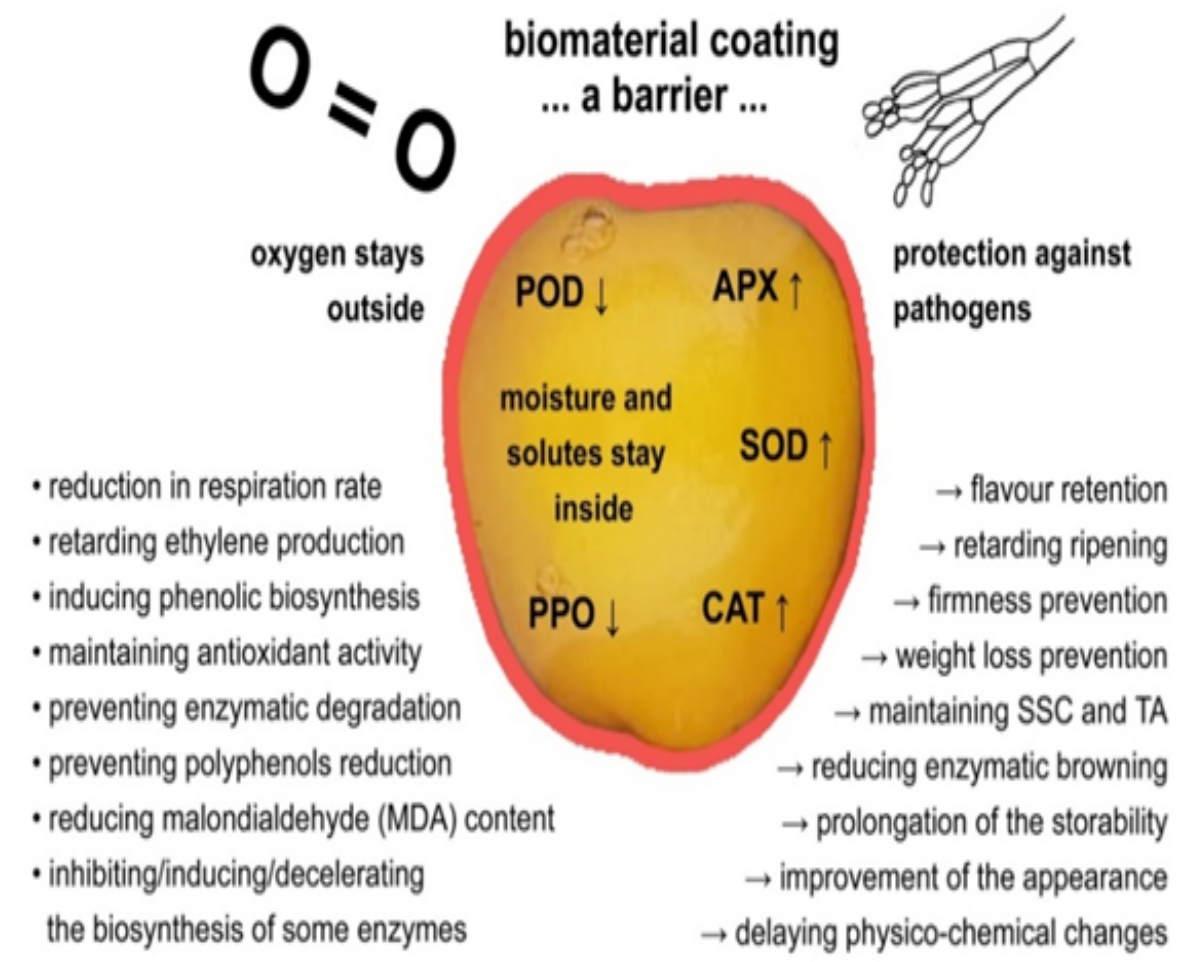

Figure I Schematic diagram of a fruit coated with edible coating.

Postharvest pathogens are among the essential postharvest losses. The hydrophobic potential of the biomaterials provides an intense antimicrobial activity to the materials. Furthermore, there are two main mechanisms behind the antimicrobial activity of biomaterials, which are i) direct prevention of the pathogen growth with some biochemical reactions and ii) indirect prevention of pathogens by improving products tolerance to pathogens by induction of some enzymes. ${ }^{17}$ On the other hand, there are some disadvantages, which make it challenging to develop and commercialize such practices. These are lack of knowledge, potential allergic reactions on different products, food safety issues, sensory implications and high costs. ${ }^{3,9}$ The activity of the biomaterials can also be improved with the incorporation of some emulsifiers (stearic acid or soy lecithin) and/ or surfactants (Tweens) which mainly aid the adhesion ability of biomaterials. ${ }^{18,19}$ The combination of the different biomaterials can also have higher efficacy in preserving food quality. ${ }^{20}$

\section{Conclusion}

To sum up, the development and use of those biomaterials in food preservation practices are thought to be so crucial for the preservation of food quality and ensuring food safety in the future. The selection of the right materials is utmost necessary to obtain better success in quality retention. This is significantly related with the material's structure, such as proteins provide an excellent barrier to gaseous but may have some allergenic risks, ${ }^{21}$ where on the other hand, lipids have low gas but sound moisture barrier. Additional to these, polysaccharides have a high ability to be a barrier to both gaseous and moisture. ${ }^{9}$ Besides that, the food type is also essential where it significantly influence the success of the biomaterial. Therefore, future studies should focus on the isolation of the active compounds in the biomaterials and understanding their main mechanisms. This will help to optimize existing or newly developed techniques and help to commercialize such practices. In this case, we would like to express our satisfaction about this Special Issue with the name "Biomaterials for Food Preservations", and we believe that the valuable papers will light the way for new researchers to commercialize such techniques.

\section{Funding}

This research was funded by the Natural Science Foundation in Jiangxi Province (20181BCB24005).

\section{Acknowledgments}

None.

\section{Conflicts of interest}

The authors declare no conflict of interest.

\section{References}

1. Zhang YF, Li YP, Sun J, et al. Optimizing water resources allocation and soil salinity control for supporting agricultural and environmental sustainable development in Central Asia. Sci Total Environ. 2020;704:135281.

2. Kahramanoğlu İ. Introductory chapter: postharvest physiology and technology of horticultural crops. In: Kahramanoğlu I, editor. Postharvest Handling, London, InTech Open, 2017:1-5. 
3. Riva SC, Opara UO, Fawole OA. Recent developments on postharvest application of edible coatings on stone fruit: A review. Sci Hortic. 2020;262:109074.

4. Singh D, Singh SK, Modi A, et al. Impacts of agrochemicals on soil microbiology and food quality. In: Singh D, Singh SK, editors. Agrochemicals Detection, Treatment and Remediation ButterworthHeinemann, 2020:101-116.

5. Koch S, Epp A, Lohmann M, et al. Pesticide residues in food: attitudes, beliefs, and misconceptions among conventional and organic consumers J Food Prot. 2017;80(12):2083-2089.

6. Chen J, Shen Y, Chen C, et al. Inhibition of key citrus postharvest fungal strains by plant extracts in vitro and in vivo: A review. Plants. 2019;8(2):26

7. Ju J, Xie Y, Guo Y, et al. Application of edible coating with essential oil in food preservation. Crit Rev Food Sci Nutr. 2019;59(15):2467-2480.

8. Cao X, Islam MN, Chitrakar B, et al. Effect of combined chlorogenic acid and chitosan coating on antioxidant, antimicrobial, and sensory properties of snakehead fish in cold storage. Food Sci Nutr. 2020;8(2):973-981.

9. Ncama K, Magwaza LS, Mditshwa A, et al. Plant-based edible coatings for managing postharvest quality of fresh horticultural produce: A review. Food Packag. Shelf Life. 2018;16:157-167.

10. Batista DDVS, Reis RC, Almeida JM, et al. Edible coatings in postharvest papaya: impact on physical-chemical and sensory characteristics. J Food Sci Technol. 2020;57(1):274-281.

11. Nor SM, Ding P. Trends and advances in edible biopolymer coating for tropical fruit: a review. Food Res Intern. 2020;109208.

12. Kubheka SF, Tesfay SZ, Mditshwa A, et al. Evaluating the efficacy of edible coatings incorporated with moringa leaf extract on postharvest of 'maluma'avocado fruit quality and its biofungicidal effect. HortScience, 2020;1:1-6.
13. Yousuf B, Qadri OS, Srivastava AK. Recent developments in shelf-life extension of fresh-cut fruits and vegetables by application of different edible coatings: A review. LWT 2018;89:198-209.

14. Parreidt ST, Müller K, Schmid M. Alginate-based edible films and coatings for food packaging applications. Foods. 2018;7(10):170.

15. Ali S, Khan AS, Nawaz A, et al. Aloe vera gel coating delays postharvest browning and maintains the quality of harvested litchi fruit. Postharvest Biol. Technol. 2019;157:110960.

16. Maringgal B, Hashim N, Tawakkal ISMA, et al. Recent advance in edible coating and its effect on fresh/fresh-cut fruits quality. Trends Food Sci Technol. 2020;96:253-267.

17. Kahramanoğlu İ, Okatan V, Wan C. Biochemical composition of propolis and its efficacy in maintaining postharvest storability of fresh fruits and vegetables. J Food Qual. 2020;8869624.

18. Moradi F, Emamifar A, Ghaderi N. Effect of basil seed gum based edible coating enriched with echinacea extract on the postharvest shelf life of fresh strawberries. J Food Meas Charact. 2019;13(3):1852-1863.

19. Arroyo BJ, Bezerra AC, Oliveira LL, et al. Antimicrobial active edible coating of alginate and chitosan add $\mathrm{ZnO}$ nanoparticles applied in guavas (Psidium guajava L.). Food Chem. 2020;309:125566.

20. dos Passos Braga S, Magnani M, Madruga MS, et al. Characterization of edible coatings formulated with chitosan and Mentha essential oils and their use to preserve papaya (Carica papaya L.). Innov Food Sci Emerg Technol. 2020;102472.

21. de Quadros CC, Lima KO, Bueno CHL, et al. Effect of the edible coating with protein hydrolysate on cherry tomatoes shelf life. J Food Process. Preserv. 2020; 14760. 